\title{
Fatigue life predictions in polymer particle composites
}

\author{
F.V. Antunes a,*, J.M. Ferreira ${ }^{\text {a }}$, J.D. Costa ${ }^{\text {a }}$, C. Capela ${ }^{\text {b }}$ \\ ${ }^{a}$ Department of Mechanical Engineering, University of Coimbra, Pinhal de Marrocos, 3030 Coimbra, Portugal \\ ${ }^{\mathrm{b}}$ Department of Mechanical Engineering, Instituto Politécnico de Leiria, Leiria, Portugal
}

Received 26 July 2001; received in revised form 14 December 2001; accepted 10 January 2002

\begin{abstract}
This paper presents a study on fatigue life predictions in three polymer particle composites with different volume fractions of filler and different particle sizes. Central hole notched specimens were analysed using a fracture mechanics approach. A solution for the stress intensity factor of corner cracks at a hole was obtained using the finite element method and considering quarter-circular and quarter-elliptical cracks of different sizes. The solution was compared with a literature solution and significant differences were found. Fatigue crack propagation tests were performed at room temperature and constant loading amplitude, for stress ratios $R=0$ and $R=-0.75$. Finally, fatigue lives, crack shape evolution and final crack length were predicted assuming an initial crack size and considering that the crack maintains a quarter-elliptical shape. The comparison with experimental fatigue lives indicated the presence of initial defects larger than the silica particles; however, these large sizes can be explained by the residual stresses measured near the hole. (C) 2002 Elsevier Science Ltd. All rights reserved.
\end{abstract}

Keywords: $K$ solution; Corner crack at a hole; Crack shape evolution; Fatigue life prediction

\section{Introduction}

The PMMA/Si acrylic casting dispersion is a composite used as a substitute for many indoor household ceramics, such as kitchen sinks, sanitary ware or sanitary furniture. In kitchen sinks the PMMA/Si combines the ease of moulding of the PMMA with the stiffness and wear-resistance improvement provided by the reinforcement particles of silica $\left(\mathrm{SiO}_{2}\right)$. In general, the addition of rigid particles to polymers or others materials can also produce a reduction in thermal expansion, an improvement in creep resistance and fracture toughness, and so on. However, some failures had been observed in service in kitchen sinks with these materials. The cause for these fractures is probably thermal stresses due to alternated flows of cold and hot water [1,2], which can produce thermal fracture or thermal fatigue. Naturally these failures must be avoided.

Studies on fatigue of particulate composites are scarce in the literature, particularly on silica-filled PMMA poly-

* Corresponding author. Tel.: +351-2397-90722/00; fax: +3512397-90701.

E-mail address: fernando.ventura@dem.uc.pt (F.V. Antunes). mers. McMurray and Amagi [3] studied the effect of temperature and stress ratio on fatigue strength of a silica-filled epoxy resin. They studied only one volume fraction $(60 \%)$ of silica with an average size of $7 \mu \mathrm{m}$. The temperatures used were significantly higher $(T=60$, 80 and $100{ }^{\circ} \mathrm{C}$ ) than those considered here.

Fatigue crack growth patterns and lives can be studied numerically using experimental results of fatigue crack growth rate and fracture toughness. A first approach considers only some crack front key points (usually the surface and deepest points) and assumes a particular crack shape during all crack growth (usually circular or elliptical) [4]. The crack is only allowed to change its aspect ratio with crack growth. The constants $C$ and $m$ of the Paris law equation are determined experimentally at the desired stress ratio. An effective $\Delta K$ can be used to account for crack closure. This methodology has been widely used in practical assessments of fatigue crack propagation and good agreement was found with experimental results [5,6]. Smith and Cooper [7] proposed an alternative approach that considers several points along the crack front and studies its propagation with the application of load cycles. $K$ along the crack front is calculated by a three-dimensional finite element analysis or boundary element analysis, and an appropriate Paris law 


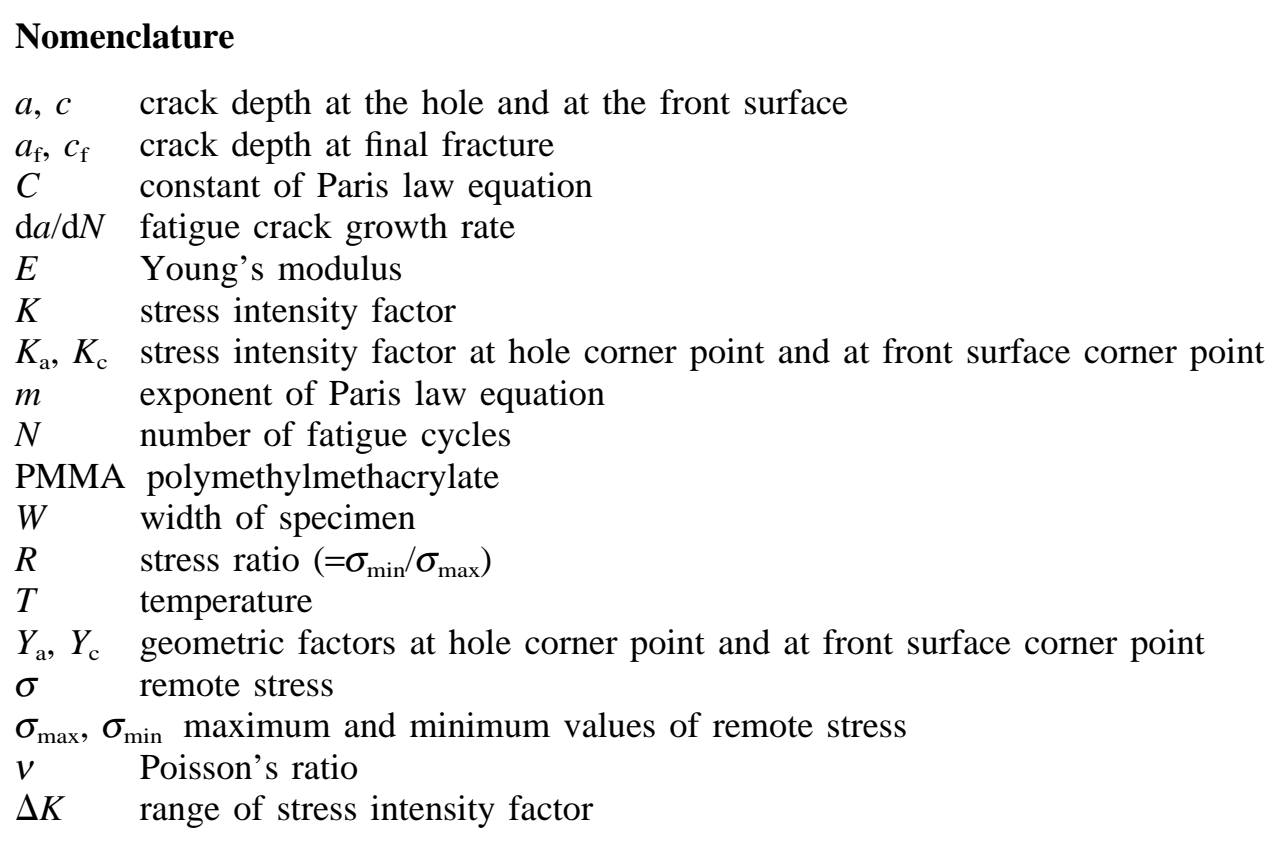

equation is integrated to obtain several local crack growth increments, from which a new crack front can be defined. The first approach will be used here because Lin and Smith [8] showed that symmetric corner cracks at a hole maintain a quarter-elliptical shape during their growth.

The main objective of this paper is to assess the risk of fatigue failure of PMMA reinforced with silica particles. Three different volume fractions of filler and different particle sizes were considered. Fatigue lives, crack shape evolution and final crack length were predicted for central hole specimens using a $K$ solution, $\mathrm{d} a / \mathrm{d} N-\Delta K$ curves and assuming a quarter-elliptical shape and an initial size for the defects. Two solutions of $K$ were considered: a numerical solution obtained here using the finite element method and a solution found in the literature. Fatigue lives were also determined experimentally and compared with predictions.

\section{Materials and testing conditions}

The materials studied in this work were acrylic casting dispersions with different volume fractions and sizes of silica particles. Table 1 presents the chemical and physical composition for the three composites, whose trademarks are Asterite, Amatis and Ultra-Quartz [9]. Table 2 presents the mechanical properties of these materials. The increase in volume fraction and size of the silica particles increases Young's modulus but reduces tensile strength. The fracture toughness is lower for Asterite, the material with a lower content of silica, and higher for Amatis.
Table 1

The chemical and physical composition of the materials tested [9]

\begin{tabular}{|c|c|c|c|c|}
\hline \multirow[t]{2}{*}{$\begin{array}{l}\text { Material } \\
\text { (trade mark) }\end{array}$} & \multicolumn{2}{|c|}{$\begin{array}{l}\text { Components and } \\
\text { volume fraction (\% } \\
\text { vol) }\end{array}$} & \multirow[t]{2}{*}{$\begin{array}{l}\text { Particle size } \\
(\mu \mathrm{m})\end{array}$} & \multirow[t]{2}{*}{ Density $\left(\mathrm{g} / \mathrm{cm}^{3}\right)$} \\
\hline & PMMA & $\mathrm{SiO}_{2}$ & & \\
\hline Asterite & 56 & 44 & 10 & 1.69 \\
\hline Amatis & 52 & 48 & 350 & 1.74 \\
\hline Ultra-Quartz & 36 & 64 & 590 & 1.92 \\
\hline
\end{tabular}

Table 2

Mechanical properties of the three materials at room temperature [2]

\begin{tabular}{lllll}
\hline Material & $\begin{array}{l}\text { Tensile } \\
\text { strength } \\
(\mathrm{MPa})^{\mathrm{a}}\end{array}$ & $\begin{array}{l}\text { Young's } \\
\text { modulus, } E \\
(\mathrm{MPa})^{\mathrm{b}}\end{array}$ & $\begin{array}{l}\text { Poisson's } \\
\text { ratio, } \nu(-)^{\mathrm{b}}\end{array}$ & $\begin{array}{l}\text { Fracture } \\
\text { toughness, } \\
K_{\mathrm{c}}(\mathrm{MPa} \\
\left.\mathrm{mm}^{-1 / 2}\right)^{\mathrm{c}}\end{array}$ \\
\hline Asterite & 65 & 8875 & 0.24 & 48 \\
Amatis & 38 & 8056 & 0.26 & 77 \\
Ultra-Quartz & 22 & 13449 & 0.22 & 60 \\
\hline
\end{tabular}

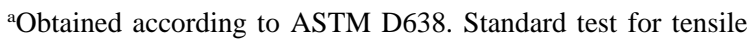
properties of plastics.

${ }^{\mathrm{b}}$ Determined by extensometry, testing a rectangular cross-section tension specimen with four strain gauges bonded along longitudinal and transverse directions.

${ }^{\mathrm{c}}$ Obtained according to EGF task group on polymers and composites. A linear elastic fracture mechanics standard for determining $K_{\mathrm{c}}$ and $G_{\mathrm{c}}$ for plastics. Testing protocol for $K_{\mathrm{c}} / G_{\mathrm{c}}$ standard, May 1988. 
Specimens of the three materials were submitted to constant amplitude fatigue tests in order to obtain their fatigue lives. The geometry of the specimens used in the tests is shown in Fig. 1. They were obtained from the bottom of kitchen sinks taken from a production line. Tungsten carbide tools were used to machine the specimens due to the abrasive nature of these materials. After machining, the specimens were polished mechanically. All tests were carried out in tension in a servo-hydraulic machine Instron (model 1341) in load control, at room temperature. A sinusoidal waveform was used with frequencies in the range $30-40 \mathrm{~Hz}$. Thermal stresses were obtained experimentally by extensometry in another study (in preparation). The ratio between the compression and the tension stresses were close to -0.75 . Therefore, it was this $R$ ratio that was used in the fatigue tests. The stress ratio $R=0$ was also used because it is always an important value for material characterization. The results will be presented on the form of $S-N$ Wohler curves.

Fatigue crack propagation tests were also carried out using MT specimens according to the ASTM E647 standard [10]. These tests were conducted under the same conditions used in the above tests. The compliance technique was adopted to measure the crack length. Previously, a crack length calibration curve was generated. For this, several crack lengths were artificially created with the aid of a small bandsaw. For each crack length a load versus strain plot was generated to obtain the ratio $\Delta \sigma /(E \Delta \varepsilon), \Delta \sigma / E$ being the applied remote strain and $\Delta \varepsilon$ the local strain measured by a strain gauge bonded to the specimen above the specimen hole. Then the calibration curve was plotted as the ratio $\Delta \sigma /(E \Delta \varepsilon)$ against crack

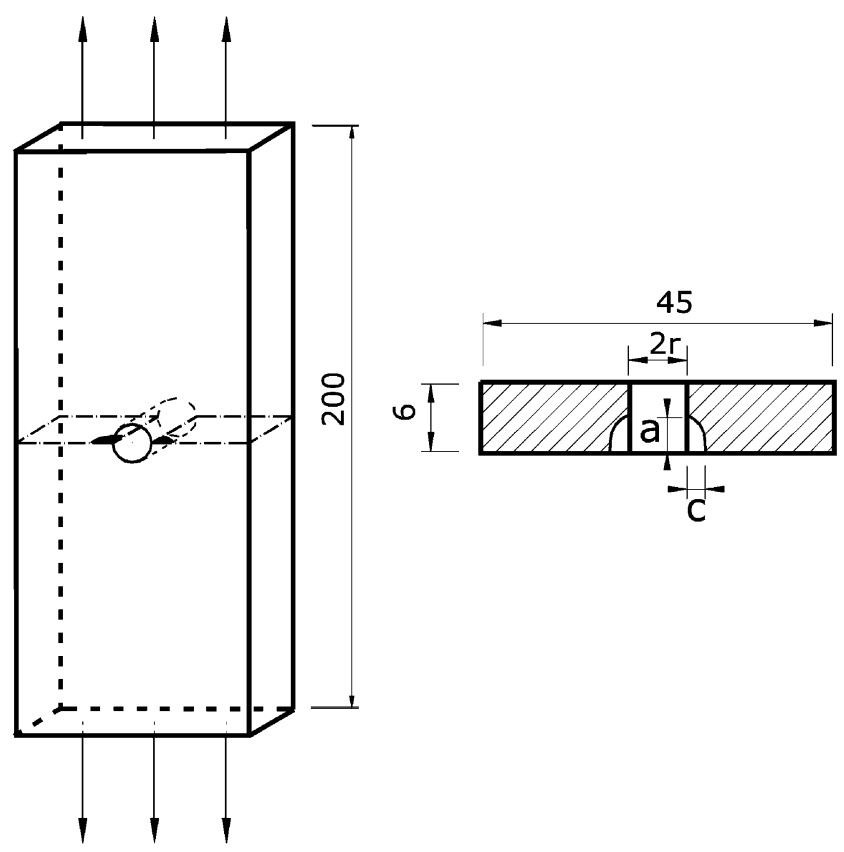

Fig. 1. Specimen with central hole and symmetrical corner cracks.

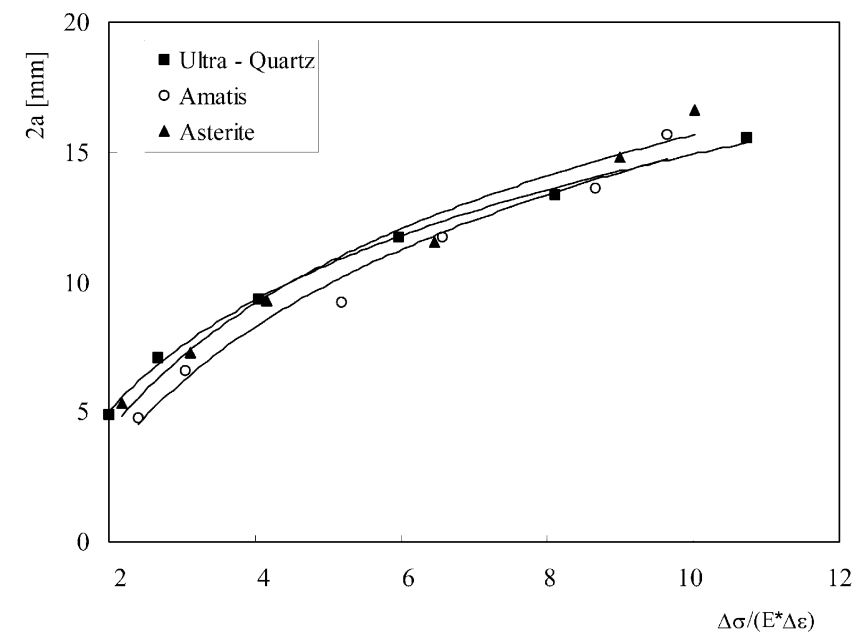

Fig. 2. Calibration curves for $R=0$.

length $2 a$. Fig. 2 presents the calibration curves for Asterite, Amatis and Ultra-Quartz loaded at $R=0$. Similar results were obtained for $R=-0.75$.

The average residual stresses in the inner points of central hole specimens, introduced by the manufacture of the hole, were measured in some of the specimens of Asterite using the hole-drilling technique. This technique consists in the application of a gauge rosette onto the specimen. Then, special tools are used to drill a hole in the centre of the strain gauge. Following this action, residual stresses change the strains on the surface of the specimen, which is detected by the strain gauge rosette, and then used for calculating the residual stress state.

\section{Results}

\subsection{Stress intensity factor $(K)$ solution}

It is important to have accurate stress intensity factor solutions, otherwise incorrect fatigue lives will be predicted. A $K$ solution was determined numerically for the corner crack studied here. Fig. 3 presents the physical model considered in the finite element method analysis. Only a quarter part of the geometry was analysed, considering adequate symmetry conditions. A static load of $1350 \mathrm{~N}$ was applied to this model for calculation of $K$,
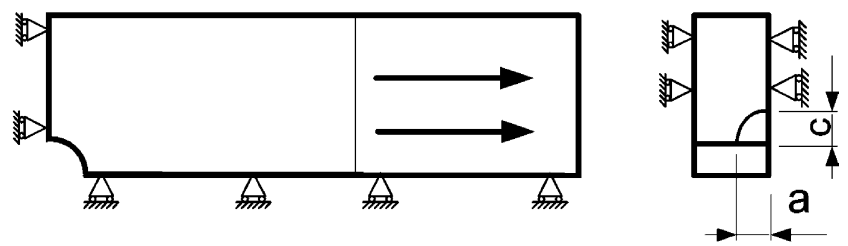

Fig. 3. Physical model considered in the finite element method analysis. 
which corresponds to a remote stress of $10 \mathrm{MPa}$. Since the load is normal to the crack section, mode I deformation occurs along all of the crack front. Rotation and flexure of the head of the specimen was restrained, which was intended to simulate the boundary conditions imposed by the grips of the loading machine. The linear elastic properties considered were $E=13000 \mathrm{MPa}$ (Young's modulus) and $v=0.225$ (Poisson's ratio).

The finite element code used was MODULEF [11]. The calculations were made with double precision numbers to reduce round-off errors. Isoparametric pentahedric singular elements (with mid-side nodes positioned at quarter-point positions) were considered around the crack front. 3D isoparametric elements were considered elsewhere: 20 node hexahedral elements and 15 node pentahedric elements. A full Gauss integration was used for these elements, i.e. $3 \times 3 \times 3$ integration points for the hexahedric elements and 21 integration points for the pentahedric elements. Fig. 4a presents the mesh used in the analysis of a $1 \mathrm{~mm}$ quarter-circular crack, which has 948 elements and 4346 nodes. Fig. 4b presents the finite element mesh around the crack front. The mesh was refined near the free surfaces to account for surface effects. The nodes along the crack front were positioned on a cubic spline, which provides a good simulation of the real shape (better than a polygonal line). This mesh was adapted for different sizes and shapes of crack. The stress intensity factor $(K)$ was calculated using a direct method proposed by Zhu and Smith [12], which considers two nodes and the distribution of displacements near the crack tip divided into two terms (a singular term and a non-singular term).

Figures $5 \mathrm{a}$ and $5 \mathrm{~b}$ present the results obtained for quarter-circular cracks $(a / c=1)$, while Figs $5 \mathrm{c}$ and $5 \mathrm{~d}$ present the results obtained for quarter-elliptical cracks with $a / c=2$ (see Fig. 1). The stress intensity factor was also calculated using the external forces method [13]. In this method, several virtual crack increments are considered and the work of external forces $\left(W_{\mathrm{E}}\right)$ is calculated for each crack configuration using the finite element method. The values of $W_{\mathrm{E}}$ and $\Delta A$, the virtual increment of the crack area, are used to calculate the energy release rate, from which $K$ can be obtained. A good agreement was found with the results of Tables 3 and 4, the differences being lower than $2.5 \%$. The numerical results were compared with a solution proposed by Newman and Raju [15], based on numerical results published earlier [14] (Fig. 5). Differences within $-15.8 \%$ to $+14.5 \%$ were found for $Y_{\mathrm{c}}$, while for $Y_{\mathrm{a}}$ the differences varied from -10.1 to $3.3 \%$. These differences can be explained by extrapolation difficulties of Newman's solution. In fact, the results of reference [14] were obtained for specimens with large width $(b /(r+c)>5, b$ being the halfwidth of the cracked plate, $r$ the radius of the hole and $c$ the crack length at the front surface) and in solution [15] an approximate finite-width correction parameter (a)

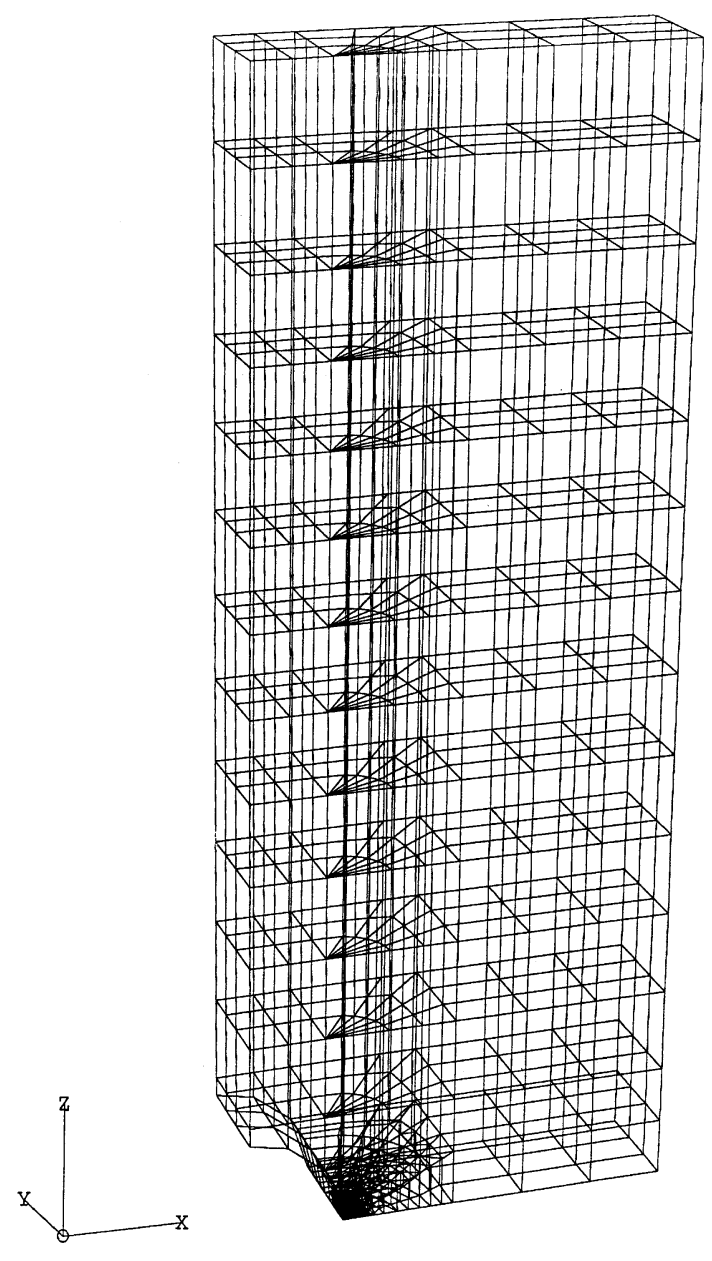

(b)

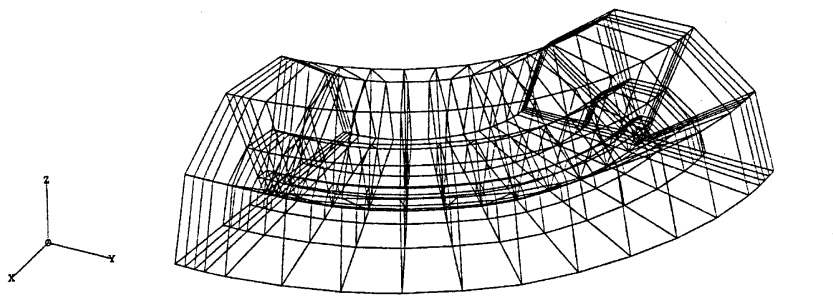

Fig. 4. Finite element mesh used in the analysis of a $1 \mathrm{~mm}$ quartercircular crack (948 elements and 4346 nodes).

was considered which extrapolates the results to geometries such that $b /(r+c)>2$.

To obtain a stress intensity factor solution several cracks were considered, with different sizes and shapes, and the surface values of $K\left(K_{\mathrm{a}}, K_{\mathrm{c}}\right)$ were obtained. The shapes analysed were $a / c=0.75,1,1.25,1.5,1.75$ and 2 , while the crack lengths were $a / t=0.05,0.1,0.2,0.3,0.4$, $0.5,0.6,0.7$ and 0.8 , where $a$ is the crack length at the hole, $c$ is the crack length at the front of the specimen and $t$ is the thickness of the specimen $(6 \mathrm{~mm})$, as represented in Fig. 1. Tables 3 and 4 present the results obtained for the geometric factors at the front surface corner point $\left(Y_{\mathrm{c}}\right)$ and at the hole corner point $\left(Y_{\mathrm{a}}\right)$. Two 
(a)

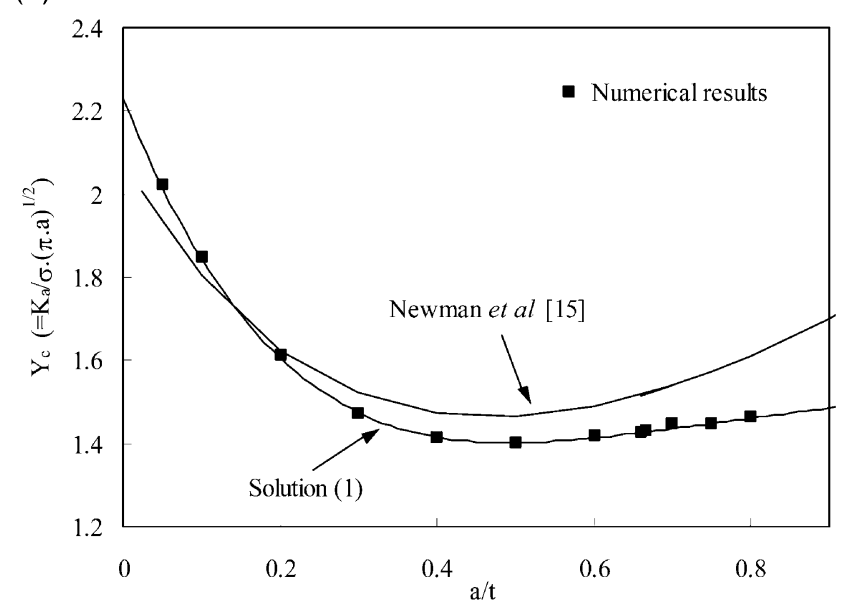

(b)

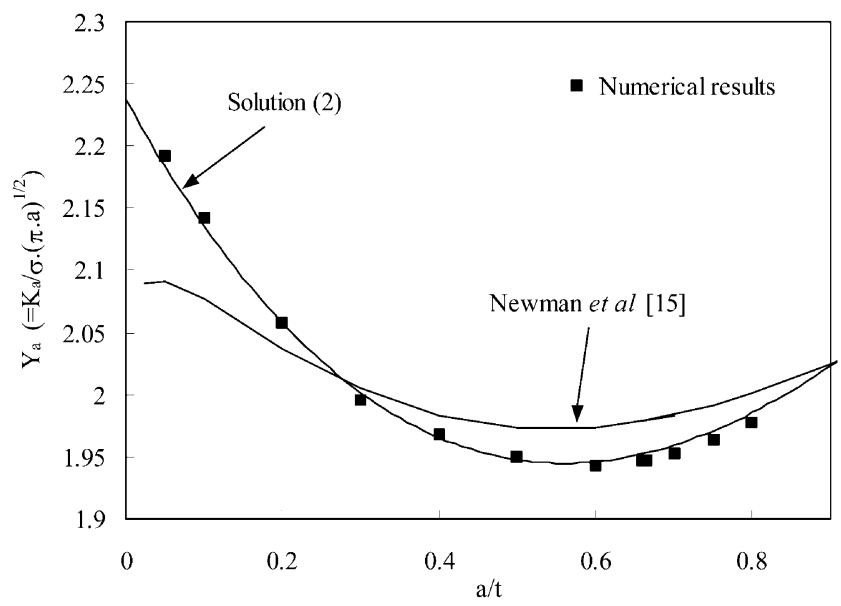

(c)

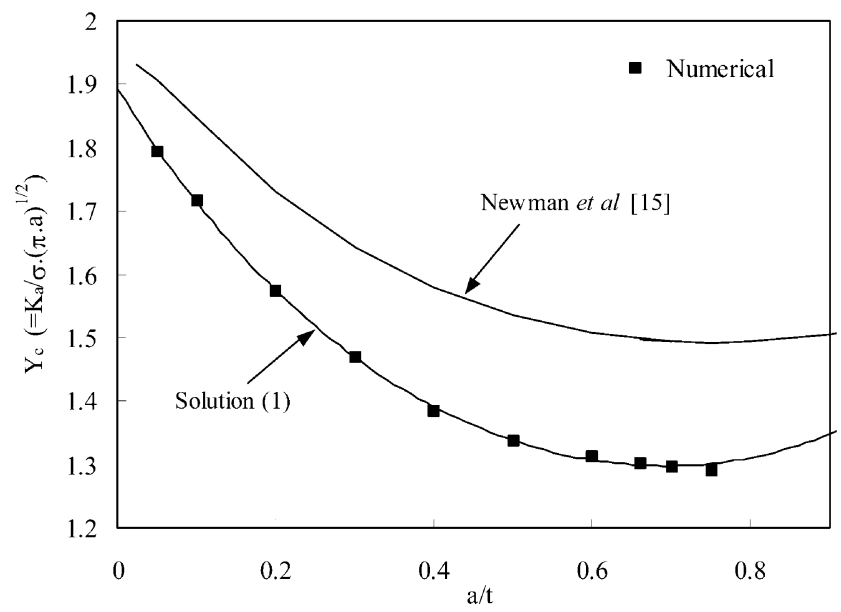

(d)

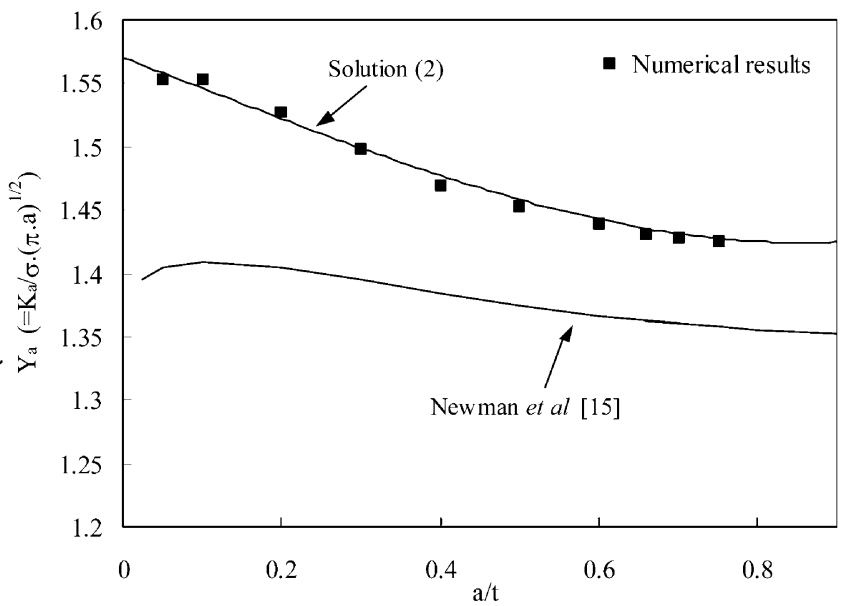

Fig. 5. Geometric factor at: (a) front surface corner point $\left(Y_{\mathrm{c}}\right)$ and (b) hole corner point $\left(Y_{\mathrm{a}}\right)$ for $a / c=1$ (quarter-circular cracks); (c) front surface corner point $\left(Y_{\mathrm{c}}\right)$ and $(\mathrm{d})$ hole corner point $\left(Y_{\mathrm{a}}\right)$ for $a / c=2$.

Table 3

Geometric factor for front surface corner point, $Y_{\mathrm{c}}$

\begin{tabular}{lllllll}
\hline & \multicolumn{6}{c}{$a / c$} \\
\cline { 2 - 7 }$a l t$ & 0.75 & 1 & 1.25 & 1.5 & 1.75 & 2 \\
\hline 0.05 & 1.987 & 2.022 & 1.986 & 1.927 & 1.86 & 1.792 \\
0.1 & 1.776 & 1.849 & 1.842 & 1.811 & 1.767 & 1.718 \\
0.2 & 1.519 & 1.612 & 1.635 & 1.627 & 1.604 & 1.574 \\
0.3 & 1.394 & 1.475 & 1.506 & 1.505 & 1.49 & 1.468 \\
0.4 & 1.36 & 1.415 & 1.428 & 1.422 & 1.405 & 1.384 \\
0.5 & 1.378 & 1.403 & 1.399 & 1.383 & 1.362 & 1.338 \\
0.6 & 1.396 & 1.419 & 1.394 & 1.367 & 1.34 & 1.312 \\
0.7 & 1.475 & 1.448 & 1.372 & 1.365 & 1.329 & 1.295 \\
0.75 & - & 1.45 & 1.392 & 1.326 & - & 1.29 \\
0.8 & - & 1.465 & 1.386 & 1.325 & - & - \\
\hline
\end{tabular}

Table 4

Geometric factor for the corner point at the hole, $Y_{\mathrm{a}}$

\begin{tabular}{lllllll}
\hline & \multicolumn{6}{c}{$a / c$} \\
\cline { 2 - 7 }$a l t$ & 0.75 & 1 & 1.25 & 1.5 & 1.75 & 2 \\
\hline 0.05 & 2.384 & 2.192 & 2 & 1.831 & 1.683 & 1.554 \\
0.1 & 2.319 & 2.143 & 1.965 & 1.811 & 1.674 & 1.553 \\
0.2 & 2.218 & 2.058 & 1.902 & 1.762 & 1.638 & 1.527 \\
0.3 & 2.156 & 1.996 & 1.853 & 1.72 & 1.603 & 1.499 \\
0.4 & 2.14 & 1.968 & 1.813 & 1.683 & 1.571 & 1.469 \\
0.5 & 2.138 & 1.949 & 1.796 & 1.665 & 1.554 & 1.453 \\
0.6 & 2.135 & 1.942 & 1.779 & 1.648 & 1.538 & 1.439 \\
0.7 & 2.174 & 1.952 & 1.778 & 1.637 & 1.525 & 1.428 \\
0.75 & - & 1.964 & 1.787 & 1.641 & - & 1.426 \\
0.8 & - & 1.977 & 1.797 & 1.649 & - & - \\
\hline & & & & &
\end{tabular}


polynomial functions were fitted by regression to these results. For the front surface corner point (crack length c):

$Y_{\mathrm{c}}=1.871+1.063 x_{2}-0.884 x_{2}^{2}+0.179 x_{2}^{3}$

$-12.927 x_{1}+13.954 x_{2} \cdot x_{1}-7.22 x_{2}^{2} \cdot x_{1}$

$+1.486 x_{2}^{3} \cdot x_{1}+47.697 x_{1}^{2}-72.579 x_{2} \cdot x_{1}^{2}$

$+43.773 x_{2}^{2} \cdot x_{1}^{2}+9.408 x_{2}^{3} \cdot x_{1}^{2}+69.24 x_{1}^{3}$

$+123.298 x_{2} \cdot x_{1}^{3}-79.475 x_{2}^{2} \cdot x_{1}^{3}+17.389 x_{2}^{3} \cdot x_{1}^{3}$

$+37.433 x_{1}^{4}-72.051 x_{2} \cdot x_{1}^{4}+47.494 x_{2}^{2} \cdot x_{1}^{4}$

$-10.339 x_{2}^{3} \cdot x_{1}^{4}$

where $Y_{\mathrm{c}}=K_{\mathrm{c}} /\left(\sigma \cdot(\pi \cdot a)^{1 / 2}\right), x_{1}=a / t, x_{2}=a / c$. For the corner point at the hole (crack length $a$ ):

$Y_{\mathrm{a}}=3.227-3.075 x_{1}+5.613 x_{1}^{2}-2.519 x_{1}^{3}-1.15 x_{2}$

$+2.446 x_{1} \cdot x_{2}-5.845 x_{1}^{2} \cdot x_{2}+3.103 x_{1}^{3} \cdot x_{2}+0.161 x_{2}^{2}$

$-0.514 x_{1} \cdot x_{2}^{2}+1.508 x_{1}^{2} \cdot x_{2}^{2}-0.886 x_{1}^{3} \cdot x_{2}^{2}$

where $Y_{\mathrm{a}}=K_{\mathrm{a}} /\left(\sigma \cdot(\pi \cdot a)^{1 / 2}\right), x_{1}=a / t, x_{2}=a / c$. The maximum differences between the numerical results (Tables 3 and 4) and solutions (1) and (2) were found to be $1 \%$ and $0.6 \%$, respectively. These solutions can be used for $0.5 \leq a / c \leq 2.5$ (extrapolation outside $0.75 \leq a / c \leq 2$ ) and for $0 \leq a / t \leq 1$ (extrapolation outside $0.05 \leq a / t \leq 0.8$ ). The error is probably within $3 \%$.

\section{2. $d a / d N-\Delta K$ curves}

Figures $6 \mathrm{a}$ and $6 \mathrm{~b}$ present the fatigue crack propagation rate $\mathrm{d} a / \mathrm{d} N$ against the stress intensity factor range $\Delta K$ for $R=0$ and $R=-0.75$, respectively, at room temperature $\left(T=20^{\circ} \mathrm{C}\right)$. For $R=-0.75, \Delta K$ was obtained considering only the positive range of $\Delta \sigma$. These composites did not exhibit a sigmoidal variation consisting of the three regimes (near-threshold, intermediate growth rate and high growth rate), typical of ductile solids. However, no results were obtained below $3 \times 10^{-7} \mathrm{~mm} /$ cycle, where the near-threshold regime could be observed. The Paris law was fitted to these results by regression, $m$ and $C$ being presented in Table 5 .

The composites materials present a great improvement in the fatigue crack growth strength relative to the PMMA matrix [16]. In the case of the Asterite composite this improvement was of about two orders of magnitude while the Ultra-Quartz shows an even greater improvement of three orders of magnitude. The Amatis shows crack growth rates intermediate between Asterite and Ultra-Quartz Paris curves. Hence, it can be concluded that the addition of the filler particles increases significantly the fatigue crack growth resistance of these materials. Also, both the size and the volume fraction of filler seem to improve the crack growth resistance. The difference between the results for different materials (b)

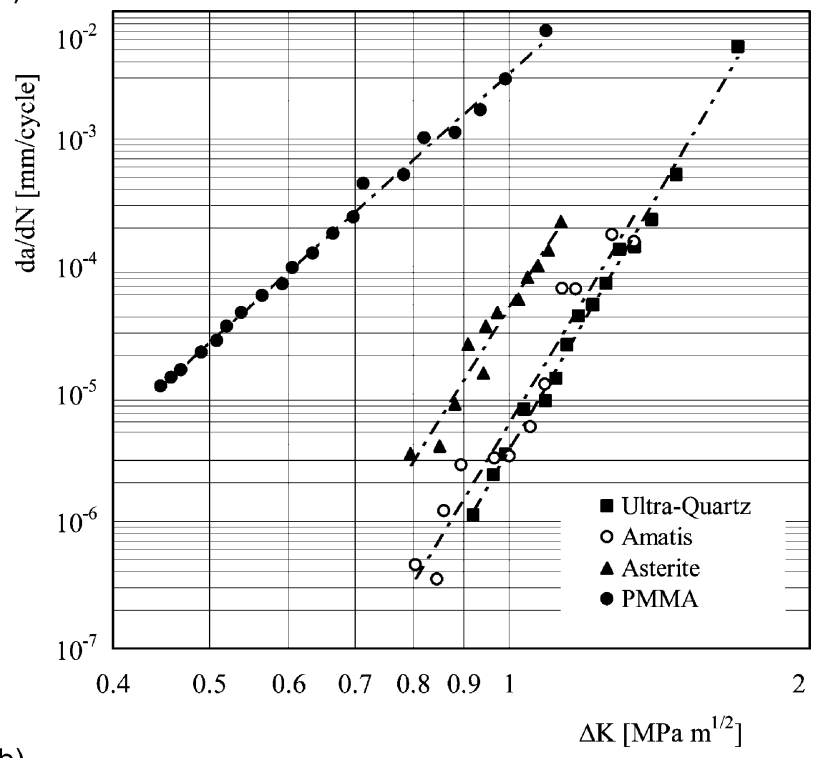

(b)

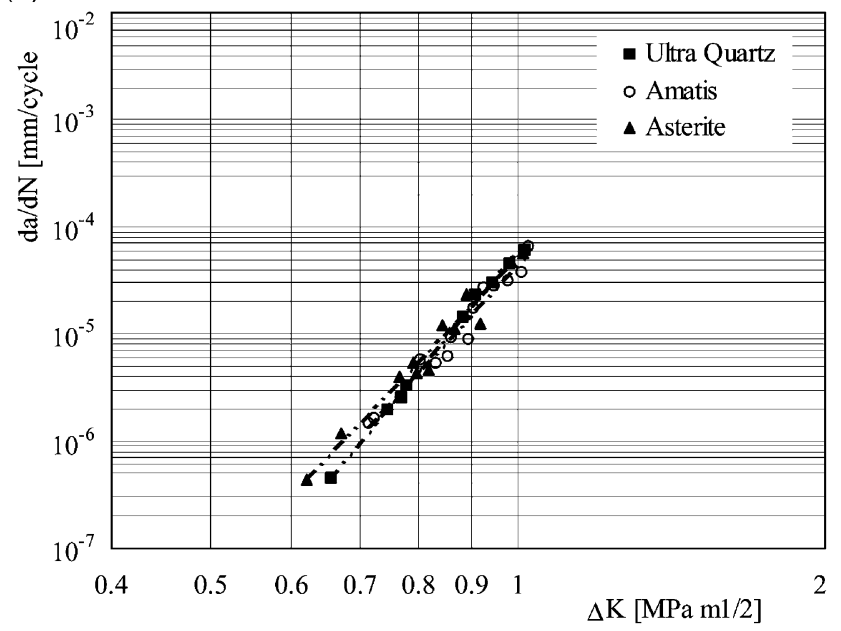

Fig. 6. $\mathrm{d} a / \mathrm{d} N-\Delta K$ curves for (a) $R=0$ and (b) $R=-0.75\left(T=20^{\circ} \mathrm{C}\right)$.

Table 5

Paris law constants $\left([\mathrm{d} a / \mathrm{d} N]=\mathrm{mm} /\right.$ cycle; $\left.[\Delta K]=\mathrm{MPa} \mathrm{m}^{1 / 2}\right)$

\begin{tabular}{lcrl}
\hline Material & $R$ & $m$ & \multicolumn{1}{l}{$C$} \\
\hline \multirow{2}{*}{ Asterite } & 0 & 12.47 & $4.83 \times 10^{-5}$ \\
& -0.75 & 9.75 & $4.803 \times 10^{-5}$ \\
Amatis & 0 & 12.91 & $5.938 \times 10^{-6}$ \\
& -0.75 & 10.10 & $5.657 \times 10^{-5}$ \\
Ultra-Quartz & 0 & 13.34 & $3.736 \times 10^{-6}$ \\
& -0.75 & 11.53 & $5.838 \times 10^{-5}$ \\
\hline
\end{tabular}

decreases from $R=0$ to $R=-0.75$. Only the positive range of $\Delta \sigma$ was considered for $R=-0.75$, which can partially explain this trend. 


\subsection{Experimental $S-N$ curves}

Fig. 7 presents the $S-N$ curves obtained experimentally for $R=0$. The total fatigue life is lower for the UltraQuartz composite, which has the greater size particles $(590 \mu \mathrm{m})$, a trend that can be explained by an increase in the initial crack size with particle size. The Asterite composite is the material with the greater total fatigue life, and presents the particles with lower size $(10 \mu \mathrm{m})$. This trend is in agreement with the static strength of the three materials.

\subsection{Numerical predictions}

Assuming the presence of a crack created in the initiation phase $\left(c_{0}, a_{0}\right)$, a fracture mechanics analysis was undertaken to estimate the crack size at which specimen failure occurs, the number of cycles required to grow the initial crack till the fracture, and the evolution of crack shape. The predictions were carried out assuming that the corner cracks maintain an elliptical shape during their growth at the central hole, and carrying out the following procedure:

First, define an initial crack, i.e. $c_{0}$ and $a_{0}$. The particle size was considered a reference value for the initial flaw size.

Second, calculate the geometric factors at the front surface and hole corner points $\left(Y_{\mathrm{c}}\right.$ and $Y_{\mathrm{a}}$, respectively) using Eqs. (1) and (2). The solution proposed by Newman and Raju [15] was also used for comparison. Calculate $\Delta K_{\mathrm{c}}$ and $\Delta K_{\mathrm{a}}$ :

$$
\begin{aligned}
& \Delta K_{\mathrm{c}}=Y_{\mathrm{c}} \cdot \Delta \cdot \sigma \sqrt{\pi \cdot a} \\
& \Delta K_{\mathrm{a}}=Y_{\mathrm{a}} \cdot \Delta \cdot \sigma \sqrt{\pi \cdot a}
\end{aligned}
$$

At this step the maximum values of $K$, i.e. $\left(K_{\mathrm{c}}\right)_{\max }$ and $\left(K_{\mathrm{a}}\right)_{\max }$, were compared with the fracture toughness of

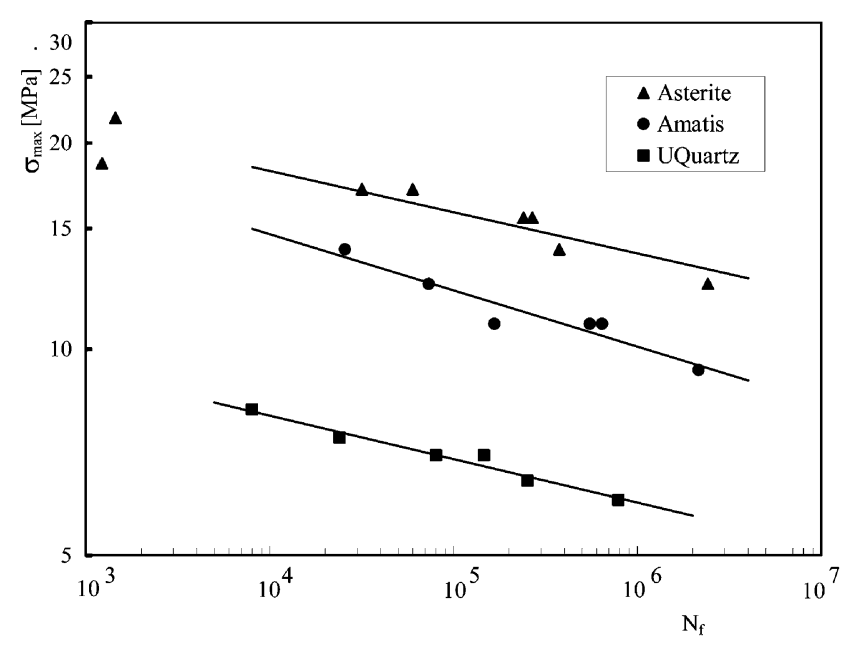

Fig. 7. $S-N$ curves for $R=0$. the material (Table 2). If $\left(K_{\mathrm{c}}\right)_{\max }$ or $\left(K_{\mathrm{a}}\right)_{\max }$ were greater than fracture toughness the analysis was stopped.

Third, calculate the crack increment using the Paris law material constants obtained in the present work (Table 5):

$$
\begin{aligned}
& \Delta c=C \cdot\left(\Delta K_{\mathrm{c}}\right)^{m} \cdot \Delta N \\
& \Delta a=C \cdot\left(\Delta K_{\mathrm{a}}\right)^{m} \cdot \Delta N
\end{aligned}
$$

The value considered for $\Delta N$ was 1 , to reduce the error introduced by considering that $\Delta K$ is constant during a crack advance.

Fourth, calculate the new crack front:

$$
\begin{aligned}
& c_{\mathrm{i}+1}=c_{\mathrm{i}}+\Delta c \\
& a_{\mathrm{i}+1}=a_{\mathrm{i}}+\Delta a
\end{aligned}
$$

and update the number of fatigue cycles:

$N_{\mathrm{i}+1}=N_{\mathrm{i}}+\Delta N$

These new crack lengths were then considered at step 2 and the procedure was repeated until the toughness of the material (given in Table 2) was attained. The size of the crack at that time is the final fatigue crack length and $N_{\mathrm{i}+1}$ is the number of fatigue cycles.

\subsection{Final crack length}

Fig. 8 presents the final fatigue crack lengths $\left(a_{\mathrm{f}}\right.$ and $c_{\mathrm{f}}$, respectively) for Asterite, Amatis and Ultra-Quartz. The initial crack lengths were chosen small enough to eliminate their influence on the shape at fracture. The increase in maximum load decreases the final crack lengths for all materials, as expected. The material significantly influences the final crack length, which is a consequence of different values of toughness (Table 2). For Asterite, the material with the lowest value of toughness, the final crack lengths are very small, shorter than

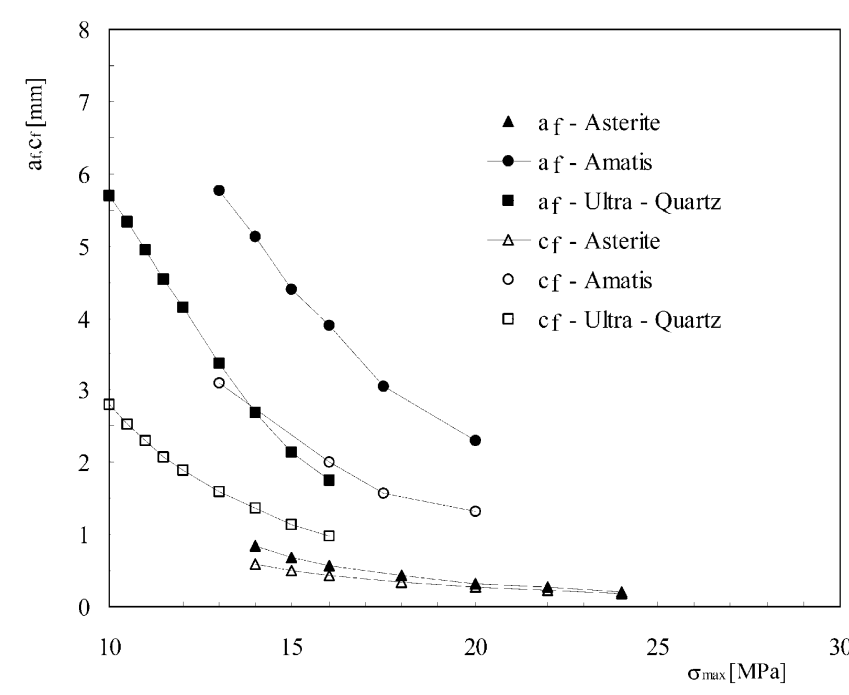

Fig. 8. Crack lengths at fracture. 
$0.6 \mathrm{~mm}$. The solution proposed in [15] was also used to obtain the final crack lengths and maximum differences of $-12 \%$ and $+22 \%$ were found for Amatis.

\subsection{Fatigue life predictions}

Figures $9 \mathrm{a}, 9 \mathrm{~b}$ and $9 \mathrm{c}$ present the life predictions obtained for Asterite, Amatis and Ultra-Quartz, respectively. For Asterite, the initial sizes predicted vary from 90 to $150 \mu \mathrm{m}$, that is much higher than the size of silica particles $(10 \mu \mathrm{m})$. For Amatis, the initial sizes predicted are within 300 to $450 \mu \mathrm{m}$, therefore similar to the particle size. For Ultra-Quartz, the initial sizes predicted are within 1.5 to $2.5 \mathrm{~mm}$, and are therefore higher than the particle size. These predictions are for propagation lives only, but if an initiation life phase was considered the initial crack sizes would be greater. The slope of the $S_{-}$ $N$ curves predicted is equal to $-1 / m$, resulting from the integration of the Paris law equation: $\Delta \sigma=N^{-1 / \mathrm{m}} \tilde{f}(Y$ $\sqrt{\pi a}, C)$. Therefore, the slope is independent of the $K$ solution and only the intercept of the curve with the stress range axis ( $Y$-axis) is affected by this.

Fig. 9b compares the predictions obtained with the two $K$ solutions being considered. The solution developed here gives fatigue lives slightly lower than those predicted with Newman's solution.

\subsection{Crack shape evolution}

Fig. 10a presents the evolution of crack shape with crack length for Asterite at $R=0$. It can be seen that the crack shape tends to about 2 with crack growth. The solution proposed by Newman and Raju [15] gives final crack shapes of about 1.5. Unfortunately, the experimental crack shapes were not detectable on the fracture surface. The experimental aspect ratio change reported by Grandt and Macha [17] in transparent PMMA is also presented in Fig. 10. The results fall between the shapes obtained with both $K$ solutions. It should be noted that the fatigue results reported by Grandt and Macha were obtained from a specimen with a single corner crack, while symmetrical cracks were considered here. In addition, the ratio $r / t$ was 1.06 , where $r$ is the radius of the hole and $t$ the thickness of the plate, that is slightly higher than considered here. Finally, parameter $m$ of the Paris law obtained by these authors was 6.1 while the experimental value of $m$ for Asterite at $R=0$ is 9.8. Fig. $10 \mathrm{~b}$ compares the evolution of crack shape for different values of $m$. It can be seen that $a / c$ decreases with $m$ as the crack approaches the opposite surface of the plate, which can explain the difference between the experimental results of Grandt and Macha [17] and the results obtained here with Eqs. (1) and (2). Lin and Smith [8] also observed a decrease in a/c with $m$. (a)

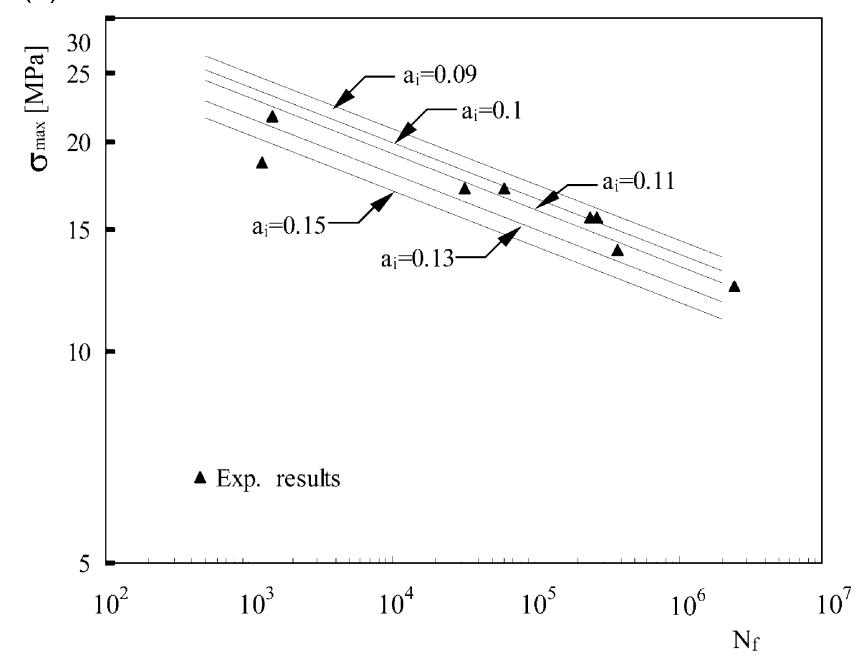

(b)

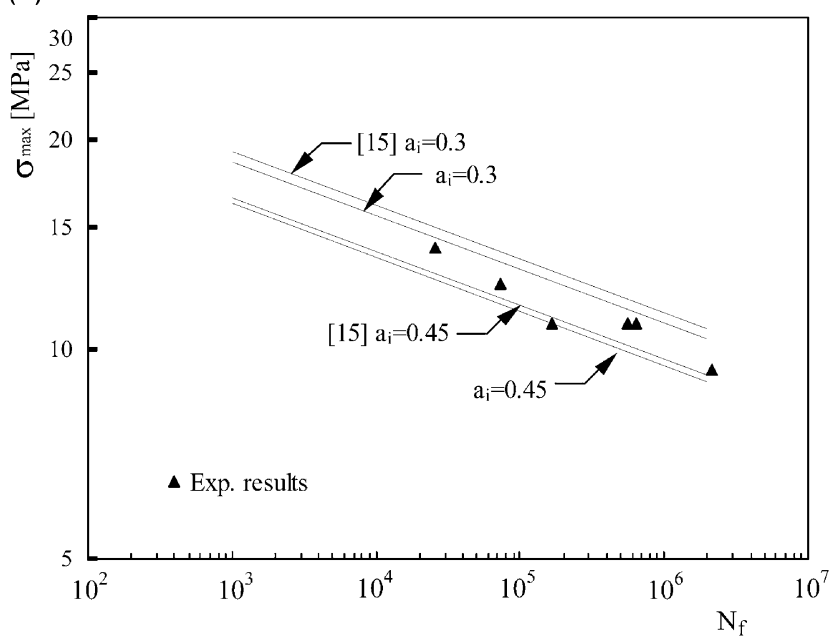

(c)

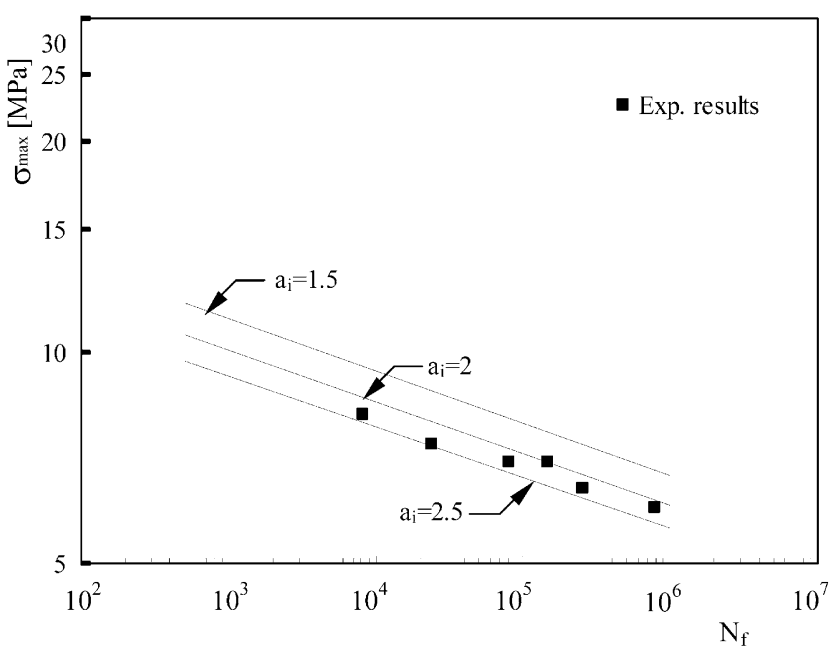

Fig. 9. (a) Asterite loaded at $R=0$. (b) Amatis loaded at $R=0$. (c) Ultra-Quartz loaded at $R=0$. 
(a)

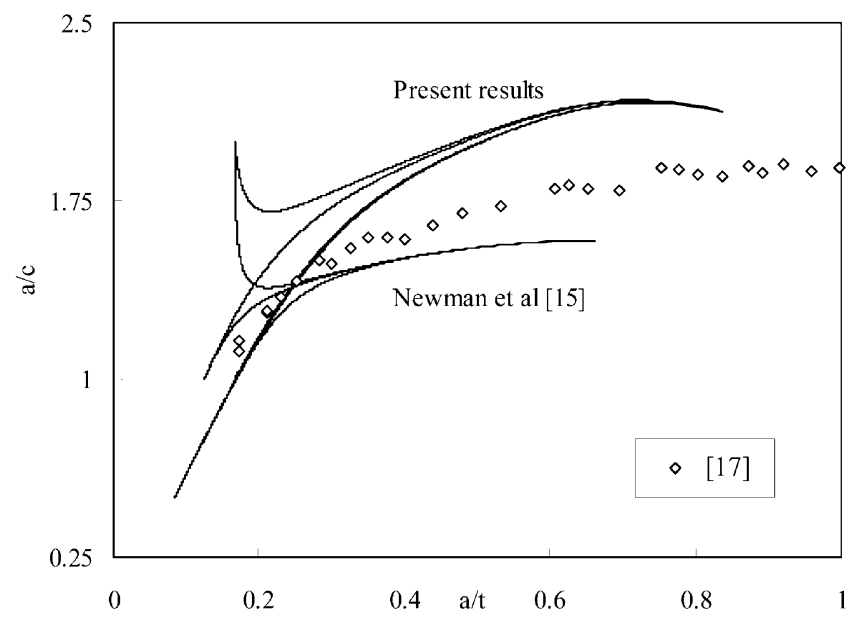

(b)

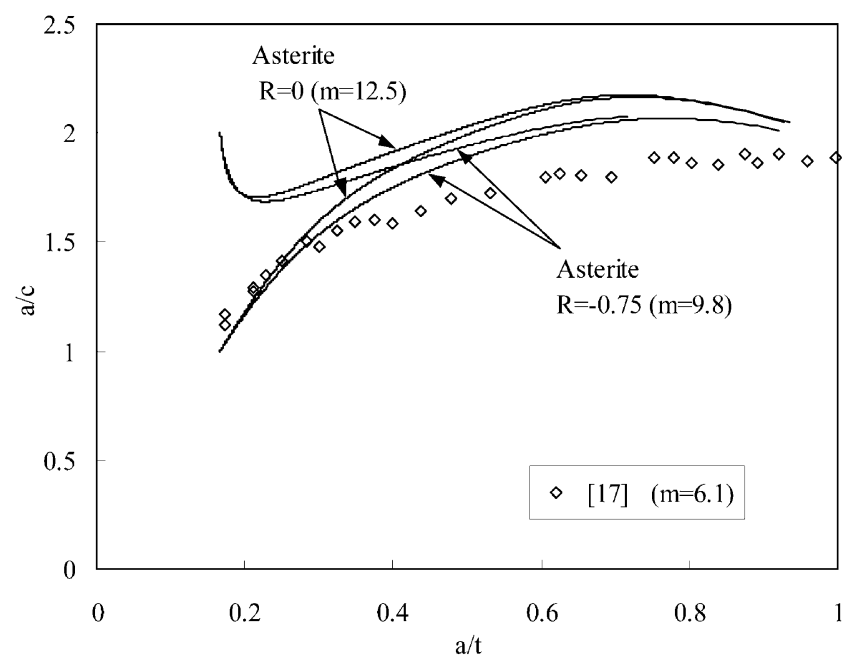

Fig. 10. (a) Evolution of crack shape for Asterite at $R=0$. (b) Influence of $m$ on crack shape evolution.

\section{Discussion}

This discussion focuses on the analysis of fatigue lives because the crack fronts were not detectable on the fracture surfaces.

Fatigue life is the summation of the life spent to initiate a crack, $N_{\mathrm{i}}$, with the life expended in subsequent propagation, $N_{\mathrm{p}}$. Sometimes, the total fatigue life becomes almost dependent on only one of these phases. In the case of particulate composite materials with a brittle matrix, like PMMA, the fatigue resistance is very dependent on the initial crack size. Hence, these materials are very sensitive to the introduction of a crack initiation site (e.g. fillers). As the particle size increases, the filler is more detrimental to overall fatigue resistance. The numerical analysis performed here only provides the propagation life, as an initial crack is assumed. The influence of particle volume fraction on fatigue crack growth rate and on fatigue strength was not analysed because it was impossible to separate this influence from the particle size influence for the three materials under analysis. However, we consider that the influence of particle size is more important, because it varies by about 60 times between Asterite and Ultra-Quartz, while the particle volume fraction vary only by about 1.5 times.

Fig. 11 present predictions of $\sigma_{\max }$ versus initial crack size for a propagation life of $10^{4}$ cycles. The experimental results for $10^{4}$ cycles are also presented, assuming that this reduced life is mainly due to propagation, i.e. that initiation life can be disregarded. These experimental results indicate an initial size for the defects.

The fatigue lives predicted for Amatis (Figs 9b and $11 \mathrm{~b}$ ), considering an initial flaw size identical to silica particle size, are similar to those obtained experimentally. This indicates that the fatigue life is almost totally spent in the propagation phase, which can be explained by the importance of the size of the silica particle. The values of the fracture toughness and the consequent final crack length (Fig. 8) also explain the reduced importance of the initiation phase. However, the results obtained for Ultra-Quartz (Figs 9c and 11c) indicate the presence of large defects, about four times larger than the size of the filler particles. That is acceptable if one assumes the joining of several silica particles where a larger defect can exist.

Finally, the fatigue lives predicted for Asterite (Figs 9a and 11a) indicate the presence of defects about 10 times higher than the size of silica particles. However, this prediction must be analysed with caution. In fact, the crack lengths are very small (Fig. 8), therefore the propagation occurs in the range of short cracks where $\mathrm{d} a / \mathrm{d} N$ is higher than expected using the fracture mechanics approach valid for long cracks. Considering this aspect, lower values of the initial crack length would be obtained, closer to the size of the silica particles. The different slopes of curves $S-N$ obtained experimentally and numerically (Fig. 9a) can be explained by the initiation life. For $\sigma_{\max }=20 \mathrm{MPa}$ the initial crack length predicted is about $100 \mu \mathrm{m}$, while for $\sigma_{\max }=14 \mathrm{MPa}$ the life predicted numerically for $100 \mu \mathrm{m}$ is lower than the life obtained experimentally. This difference can be explained by an increase in initiation life with the decrease in load, which is not considered in the numerical analysis. However, another possible explanation is the presence of traction residual stresses introduced by the manufacture of the hole. This would explain the high value predicted for the initial crack size because the residual stresses increase the stress ratio, increasing the fatigue crack growth and reducing the experimental fatigue life.

The average values of residual stress obtained at surface points close to the hole were about $30 \mathrm{MPa}$ for Asterite and $12 \mathrm{MPa}$ for Ultra-Quartz and Amatis, which 

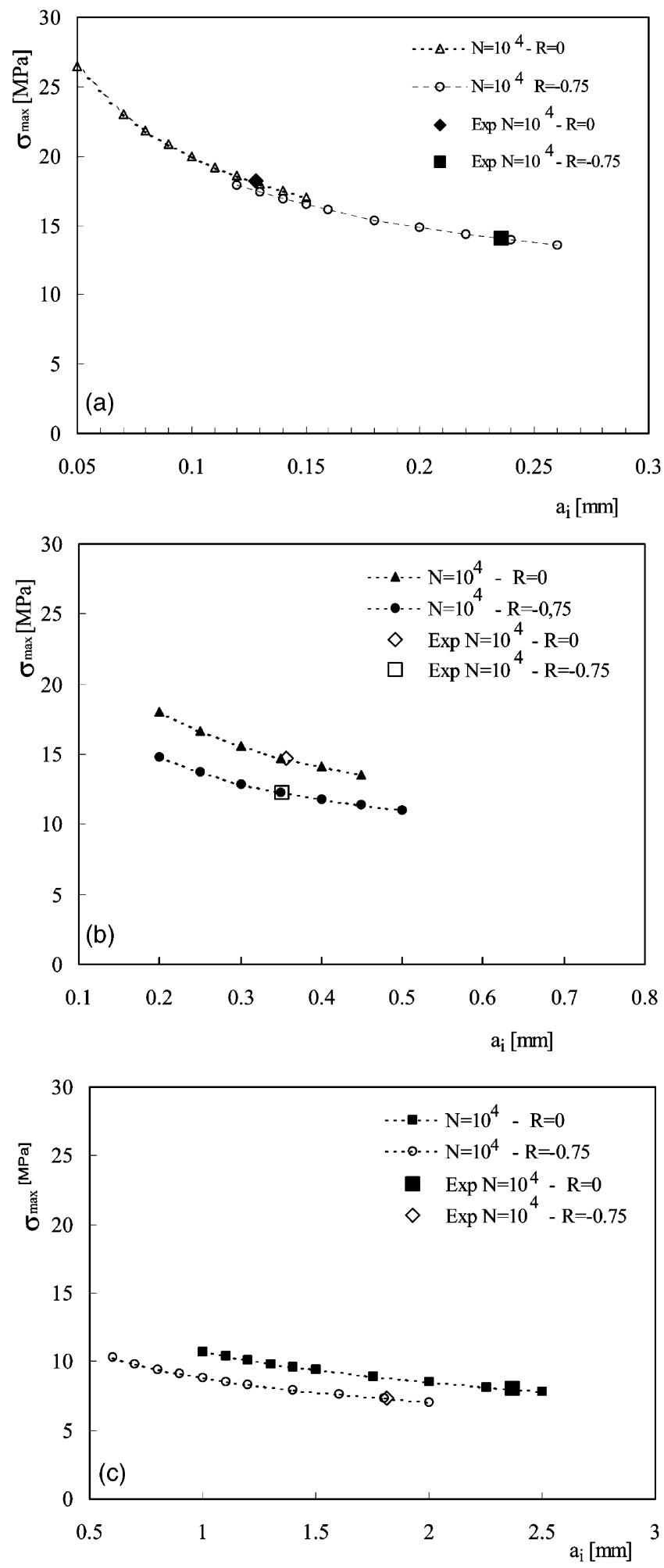

Fig. 11. Sizes predicted for initial defects: (a) Asterite; (b) Amatis; (c) Ultra-Quartz.

reduce to zero at depths larger than $300 \mu \mathrm{m}$ (Asterite) or $500 \mu \mathrm{m}$ (Ultra-Quartz and Amatis). This is particularly important for Asterite in which almost all propagation occurs inside the zone affected by residual stresses (Fig.
8). In the case of Ultra-Quartz the level of maximum stress approaches the tensile strength, the real stress ratio will be quite high and consequently the fatigue crack growth rate will be significantly higher. Therefore, the initial defects are substantially lower than predicted in Fig. 11, particularly for Asterite and Ultra-Quartz.

\section{Conclusions}

1. A $K$ solution was obtained for symmetrical corner cracks at a hole using the finite element method. This solution was compared with a literature solution and important differences were found.

2. $\mathrm{d} a / \mathrm{d} N-\Delta K$ curves were obtained. Ultra-Quartz has the lowest fatigue crack growth rate while Asterite has the worst resistance to crack growth, but still has a crack propagation rate of about two orders of magnitude below the PMMA. In fact, the addition of filler particles significantly increases the fatigue crack growth resistance of these materials relative to the PMMA matrix.

3. Tensile fatigue strength was obtained experimentally for three particulate composites using notched specimens. The material with the finest particle size (Asterite) shows a better fatigue strength while UltraQuartz with a particle size of $590 \mu \mathrm{m}$ shows the worst resistance. This trend is in agreement with the relative static strength of the three materials.

4. A fracture mechanics approach was used to predict the fatigue lives, the final crack lengths and the crack shape evolution. The final crack length was found to be very small for Asterite, in some cases below the validity of application of fracture mechanics. In the cases of Amatis and Ultra-Quartz the final crack lengths predicted were significantly higher.

5. The comparison of numerical and experimental fatigue lives indicates that for Amatis the initial crack size was similar to the size of the silica particles. In the case of Ultra-Quartz the initial crack size was predicted to be about three times higher than the size of the filler particles, which was explained by the joining of several particles. The initial defect predicted for Asterite was found to be significantly higher than the size of the silica particles, which was explained by the presence of traction residual stresses or by the short dimension of the cracks within the range of short cracks. The accuracy of the $K$ solution cannot explain the trends observed.

\section{Acknowledgements}

The authors wish to thank Sanitana-Fábrica de Sanitários de Anadia, SA, for providing the material used in the tests. 


\section{References}

[1] Ferreira JM, Costa JD, Capela C. Fracture assessment of PMMA/Si kitchen sinks made from acrylic casting dispersion. Theor Appl Fract Mech 1997;26:105-16.

[2] Capela C, Ferreira JM, Costa JD. Fracture of polymeric composites reinforced with silica particles [in Portuguese]. CIDIM'99, Santiago do Chile, 1999.

[3] McMurray MK, Amagi S. The effect of time and temperature on flexural creep and fatigue strength of a silica filled epoxy resin. J Mater Sci 1999;34:5927-36.

[4] Newman Jr. JC, Raju IS. An empirical stress intensity factor equation for the surface crack. Eng Fract Mech 1981;15:185-92.

[5] Newman Jr JC, Raju IS. Prediction of fatigue crack growth patterns and lives in three-dimensional cracked bodies. Sixth International Conference on Fracture, New Delhi, India, 4-10 December 1984.

[6] Costa JD. Analysis of defect tolerance in aluminium alloys [in Portuguese]. PhD thesis, University of Coimbra, 1991.

[7] Smith RA, Copper JF. A finite element model for the shape development of irregular planar cracks. Int J Press Vessel Piping 1989;36:315-26.

[8] Lin XB, Smith RA. Fatigue shape analysis for corner cracks at fastener holes. Eng Fract Mech 1998;59(1):73-87.

[9] Asterite, Amatis and Ultra-Quartz brochures, ICI, 1998.
[10] ASTM E647. Standard test method for measurement of fatigue crack growth rate. Annual book of ASTM standards, 03.01, USA, 1995.

[11] Institut National de Recherche en Informatique et en Automatique (INRIA). Presentation of club Module F [in French]. Le Chesnay, France, 1987.

[12] Zhu WX, Smith DJ. On the use of displacement extrapolation to obtain crack tip singular stresses and stress intensity factors. Eng Fract Mech 1995;51(3):391-400.

[13] Antunes FJV, Ferreira JAM, Byrne J. Stress intensity factor calculation based on the work of external forces. Int $\mathrm{J}$ Fract 1999;98:1-14.

[14] Raju IS, Newman Jr. JC. Stress intensity factors for two symmetric corner cracks. In: Smith CW, editor. Fracture mechanics, ASTM STP-677. 1979. p. 411-30.

[15] Newman Jr. JC, Raju IS. Stress intensity factors equations for cracks in three-dimensional finite bodies subjected to tension and bending loads. In: Atluri SN, editor. Computational methods in the mechanics of fracture. Elsevier Science Publishers BV; 1986.

[16] Costa JD, Ferreira JM, Capela C. Fatigue behaviour of PMMA/Si acrylic casting dispersions, Mater Sci Technol 2001; 17: 16571663.

[17] Grandt Jr. AF, Macha DE. Digitized measurements of the shape of corner cracks at fastener holes. Eng Fract Mech 1983;17(1):63-73. 